\title{
Pathophysiological Implication of Vitamin D in Diabetic Kidney Disease
}

\author{
David Galuška Lukáš Pácal Kateřina Kaňková \\ Department of Pathophysiology, Faculty of Medicine, Masaryk University, Brno, Czech Republic
}

\section{Keywords}

Diabetes mellitus · Vitamin D · Diabetic kidney disease .

Sodium-glucose linked co-transporter 2 inhibitors

\begin{abstract}
Background: Vitamin D is a hormone regulating not only calcium and phosphate homeostasis but also, at the same time, exerting many other extraskeletal functions via genomic effects (gene transcription) and probably by non-genomic effects as well. Availability is ensured by dietary intake of its precursors and by de novo production via sunlight. Yet, vitamin D deficiency and insufficiency are very common across the globe and are connected to many pathophysiological states, for example, diabetes mellitus, allergies, autoimmune diseases, pregnancy complications, and recently have also been associated with worse COVID-19 clinical outcomes. Summary: In this review, we summarize current knowledge about vitamin $D$ metabolism in general, its role in diabetes mellitus (mainly type 2) and diabetic complications (mainly diabetic kidney disease), and potential therapeutic perspectives including vitamin D signalling as a druggable target. Key Messages: Vitamin D is not only a vitamin but also a hormone involved in many physiological processes. Its insufficiency or deficiency can lead to many pathological states.

(c) 2021 The Author(s).

Published by S. Karger AG, Basel
\end{abstract}

karger@karger.com

www.karger.com/kbr

Karger $\stackrel{\text { ' }}{5}$

GOPEN ACCESS
(C) 2021 The Author(s)

Published by S. Karger AG, Basel

This is an Open Access article licensed under the Creative Commons Attribution-NonCommercial-4.0 International License (CC BY-NC) (http://www.karger.com/Services/OpenAccessLicense), applicable to the online version of the article only. Usage and distribution for commercial purposes requires written permission.

\section{Introduction}

Despite the significant effort in the last century to eradicate or minimize vitamin $\mathrm{D}$ deficiency among the population, especially children, there is still a high prevalence for vitamin D insufficiency/deficiency worldwide $[1,2]$. Vitamin D deficiency and insufficiency are also more common across type 2 diabetes mellitus (T2DM) patients. Furthermore, some authors suggest that vitamin $\mathrm{D}$ deficiency may be a prominent element of CKD. Vitamin $\mathrm{D}$ has to be metabolically activated in the kidney, and patients with CKD including diabetic kidney disease (DKD) are not able to produce enough of the active form of vitamin $\mathrm{D}\left(1,25(\mathrm{OH})_{2} \mathrm{D}\right)$. Vice versa, the kidneys are assumed to be a classical $1,25(\mathrm{OH})_{2} \mathrm{D}$ target. Hence, the vitamin $\mathrm{D}$ receptor (VDR) is highly expressed in kidney tissue [3-5]. Impairment of the capability of the kidney to produce and reuptake enough calcitriol and therefore maintain vitamin $\mathrm{D}$, phosphate, and calcium homeostasis is one of the principal pathophysiological components of metabolic bone disease in CKD. Also, urinary loss of both vitamin $\mathrm{D}$ and vitamin $\mathrm{D}$ binding protein (VDBP) has been reported in these individuals. With vitamin $\mathrm{D}$ concentration decreasing over time, clinical outcomes are worsening. $\mathrm{DKD}$, one of the most common forms of CKD, accounts for almost $50 \%$ of end-stage kidney disease in developed countries requiring renal replacement

David Galuška

Department of Pathophysiology, Faculty of Medicine, Masaryk University Kamenice 5

CZ-62500 Brno (Czech Republic)

423585@mail.muni.cz 
Table 1. Summary of CYP enzymes involved in the metabolism of vitamin D

\begin{tabular}{|c|c|c|c|c|c|}
\hline CYP & Localization & Also known as & Primary substrate & Secondary substrate & Product \\
\hline CYP2R1 & Microsome membrane & Vit. D 25-hydroxylase & Cholecalciferol ergocalciferol & & $25(\mathrm{OH}) \mathrm{D}$ \\
\hline CYP27A1 & Mitochondrial membrane & Sterol 27-hydroxylase & Cholecalciferol & Ergocalciferol & $25(\mathrm{OH}) \mathrm{D}$ \\
\hline CYP27B1 & Mitochondrial membrane & 1a-Hydroxylase & $25(\mathrm{OH}) \mathrm{D}$ & & $1,25(\mathrm{OH})_{2} \mathrm{D}$ \\
\hline
\end{tabular}

therapy. DKD - by itself and mostly during haemodialysis - also highly increases the risk of cardiovascular diseases such as heart attack, stroke, and others $[1,6]$.

Vitamin D is a lipid-soluble hormone and micronutrient whose primary function is to regulate calcium and phosphorus homeostasis. Vitamin D deficiency has been linked to rickets over 100 years ago. However, it has much broader effects mediated by genomic (vitamin D directly or indirectly influences expression of up to 2,000 genes) as well as non-genomic mechanisms [1]. Vitamin D deficiency also contributes to many extraskeletal outcomes, including higher risk of type 1 or type 2 diabetes mellitus, allergy, autoimmunity, pregnancy complications, and many other pathologies. A meta-analysis from 2017 connected low levels of vitamin $\mathrm{D}$ with a higher risk of respiratory tract infections [7]. A recent retrospective multicentre study statistically significantly associated lower levels of $25(\mathrm{OH}) \mathrm{D}$ with mild rather than severe COVID-19 outcomes [8]. The aims of this review are (i) to summarize recent advances in the understanding of vitamin D metabolism, (ii) to highlight its importance for human health, and (iii) to describe its role in the development of T2DM and DKD.

\section{Vitamin D Metabolism}

General term vitamin D refers to the group of lipidsoluble secosterols, also known as calciferols. Most vitamin $\mathrm{D}$ is produced in the skin (approximately 80\%) and remaining $20 \%$ is from the dietary precursors. In the upper layers of the skin, the vitamin $\mathrm{D}$ precursor 7-dehydrocholesterol is converted to previtamin $\mathrm{D}_{3}$ by UVB irradiation. Previtamin $\mathrm{D}_{3}$ then undergoes a thermal-induced rearrangement to form cholecalciferol (vitamin $\mathrm{D}_{3}$ ) in lower layers of the skin. This thermal process seems to be a rate-limiting step in vitamin $\mathrm{D}_{3}$ synthesis [9]. Vitamin $\mathrm{D}$ is also acquired from the diet in the form of cholecalciferol and ergocalciferol (vita- min $\mathrm{D}_{2}$ ). Vitamin $\mathrm{D}_{3}$, with half-life approximately $12 \mathrm{~h}$ [10], binds to VDBP which enables its transport in the blood. In the liver, carbon 25 is hydroxylated to form 25-hydroxyvitamin $\mathrm{D}_{3}\left(25(\mathrm{OH}) \mathrm{D}_{3}\right)$. Several enzymes have 25-hydroxylase activity; however, most important are CYP2R1 and CYP27A1 $[11,12]$. CYP2R1 can hydroxylate both vitamin $\mathrm{D}_{2}$ and $\mathrm{D}_{3}$ equally, while $\mathrm{CY}$ P27A1 hydroxylates vitamin $\mathrm{D}_{3}$ preferably [13]. 25-Hydroxylation is a highly efficient process; about $75 \%$ of vitamin $\mathrm{D}$ is hydroxylated during the first pass through the liver [14]. The rate of 25-hydroxylation seems to be less regulated compared to C-1 1 hydroxylation and instead depends predominantly on $\mathrm{D}_{2}$ or $\mathrm{D}_{3}$ availability [15]. Increasing evidence suggests that CYP2R1 is a major C25 hydroxylation enzyme $[15,16]$. Mutation L99P in the CYP2R1 gene eliminates its C25 hydroxylation activity, and individuals carrying this mutation suffer from vitamin $\mathrm{D}$ deficiency. Table 1 summarizes all mentioned CYPs in this review with the respective cell localization, substrate, and final products.

$25(\mathrm{OH}) \mathrm{D}$ is the main form of vitamin $\mathrm{D}$ circulating in the blood with half-life approximately 20 days [10] commonly used as an indicator of vitamin D status. However, it should be noted that $1,25(\mathrm{OH})_{2} \mathrm{D}$ has approximately $1,000 \times$ lower plasma concentration than $25(\mathrm{OH}) \mathrm{D}$, and its concentration may be sufficient or elevated even if $25(\mathrm{OH}) \mathrm{D}$ is decreased. Nonetheless, an active form of vitamin $\mathrm{D}$ is $1,25(\mathrm{OH})_{2} \mathrm{D}$, also known as calcitriol, principally formed by CYP27B1 in mitochondria of proximal tubule cells (PTC) in the kidney [17]. Furthermore, $1 a$ hydroxylation occurs also in other cell types, including parathyroid gland, cells of the immune system, or various epithelial cells $[11,12]$. This metabolic activation will be discussed further.

25-Hydroxyvitamin D-24-hydroxylase (CYP24A1) is an enzyme responsible for $25(\mathrm{OH}) \mathrm{D}$ and $1,25(\mathrm{OH})_{2} \mathrm{D}$ catabolism. Both forms can be degraded in two pathways. Mainly via C24 hydroxylation to form $24,25(\mathrm{OH})_{2} \mathrm{D}$ and $1,24,25(\mathrm{OH})_{3} \mathrm{D}$ which is then degraded to calcitroic acid. 
Another possibility is $\mathrm{C} 23$ hydroxylation which produces $\left(1,23,25(\mathrm{OH})_{3} \mathrm{D}\right.$ and $1,25(\mathrm{OH})_{2} \mathrm{D}-26 \mathrm{~S}, 23$-lactone as a final product [18]. Both metabolites are preferably excreted through bile into faeces, and only a small portion appears in the urine as $1,25(\mathrm{OH})_{2} \mathrm{D}-26 \mathrm{~S}, 23$-lactone forms a complex with VDBP [19] which is taken up by the PTC via the megalin/cubilin transporting system [20]. Human CYP24A1 is capable of hydroxylating both C23 and C24 with predominance to the C24 hydroxylation pathway [18]. Prosser et al. [21] showed that A326G mutation in the CYP24A1 gene causes shift of this ratio to the favour of the $\mathrm{C} 23$ hydroxylation pathway. Calcitroic acid is rapidly excreted into bile with no known biological activity [22]. The exact reason why two degradation pathways exist is not known. Some authors suggest that the $\mathrm{C} 23$ pathway exists as a backup [9] or safety mechanism to rapidly degrade abundant calcitriol [21]. The importance of precise maintenance of calcitriol concentration was demonstrated in a study with CYP24A1 knockout mice and CYP24A1 and VDR double knockout mice [23, 24]. CY$\mathrm{P} 24 \mathrm{~A} 1$ deletion resulted in hypercalcaemia, impaired bone mineralization, and 50\% decreased viability in experimental animals. On the contrary, CYP24A1 and VDR knockout mice did not show these characteristics. These findings suggest that increased $1,25(\mathrm{OH})_{2} \mathrm{D}$ level, not the absence of $\mathrm{C} 23$ or C24 degradation pathways, results in an abnormal phenotype.

CYPs can be divided into two main groups, based on localization within the cell: microsomal and mitochondrial (Table 1). Vitamin D metabolism includes both types. Neither microsomal nor mitochondrial CYPs work alone, but the electron transport chain is connected to them and is essential for the whole process. Mitochondrial vitamin D-related CYPs (e.g., CYP27A1, CYP27B1, and CYP24A1) require two additional electron-transporting proteins: ferredoxin reductase and ferredoxin. On the other hand, microsomal CYPs (e.g., CYP2R1) require only one additional protein, NADPH-cytochrome $\mathrm{P} 450$ reductase. All of the vitamin D-related CYPs include heme-bound structure involved in single or multiple hydroxylation process $[25,26]$.

\section{Vitamin D Metabolism in the Kidney}

Vitamin D present in the glomerular filtrate (bound to VDBP) is taken up by the kidney proximal tubular epithelial cells via the megalin/cubilin endocytic system (see Fig. 1) [27]. Degradation of VDBP in lysosome releases free $25(\mathrm{OH}) \mathrm{D}$ that is subsequently converted to

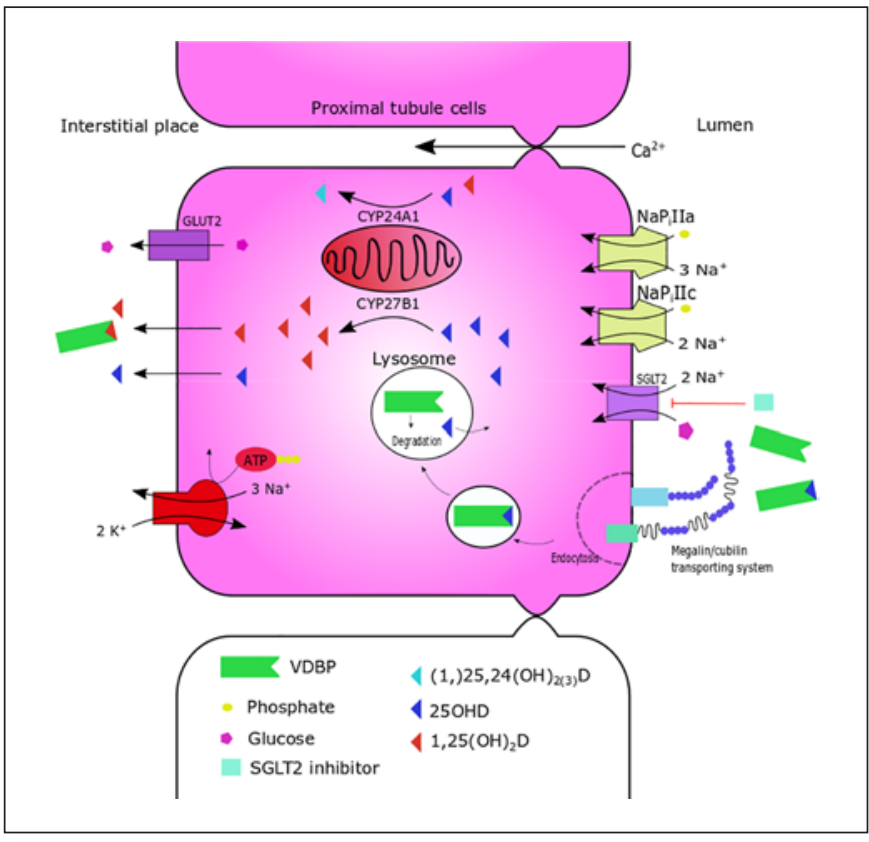

Fig. 1. Vitamin D and glucose-related transporting mechanisms in the PTC. Vitamin D binds to VDBP in the tubular lumen, and the complex is transported by the megalin/cubilin system into the PTC. Inside the cell, vitamin D is released and metabolized (activated or degraded) in mitochondria while the megalin/cubilin complex is degraded in lysosomes. Vitamin D diffuses into interstitial space where it binds to VDBP. Glucose is transported to the PTC via SGLT2. Inhibition of SGLT2 by SGLT2i increases the amount of $\mathrm{Na}^{+}$in the tubular lumen, which can increase resorption of phosphate and further alters the PTH-vitamin D-FGF23 axis. PTC, proximal tubule cell; VDBP, vitamin D binding protein; SGLT2, sodium-glucose co-transporter $2 ; \mathrm{NaP}_{\mathrm{i}}$-IIa/c, sodiumphosphate co-transporter IIa/c; GLUT2, glucose transporter 2 .

$1,25(\mathrm{OH})_{2} \mathrm{D}$ by CYP27B1 located in the inner mitochondrial membrane. $1,25(\mathrm{OH})_{2} \mathrm{D}$ is then released to the circulation by passive diffusion across the cytoplasmatic membrane. Most of $1,25(\mathrm{OH})_{2} \mathrm{D}$ in plasma is bound to VDBP and albumin $[28,29]$. Human CYP27B1 is a 507 -amino acid protein $(55 \mathrm{kDa})$ encoded by the gene localized on the 12q14.1 chromosome with a length of 4.8 $\mathrm{kb}[14,26]$.

As previously mentioned, proximal tubular epithelial cells are major players in $1 \alpha$ hydroxylation catalyzed by mitochondrial enzyme CYP27B1 [17]. Kidneys are able to ensure sufficient production of $1,25(\mathrm{OH})_{2} \mathrm{D}$. However, a number of other cell types also expresses CYP27B1 (e.g., $\mathrm{s}$, the brain, placenta, colon, pancreas, prostate, intestine, lung, macrophages, lymphocytes, parathyroid gland, osteoblasts, and chondrocytes, whose physiological significance is not clear in many cases) $[30,31]$. 


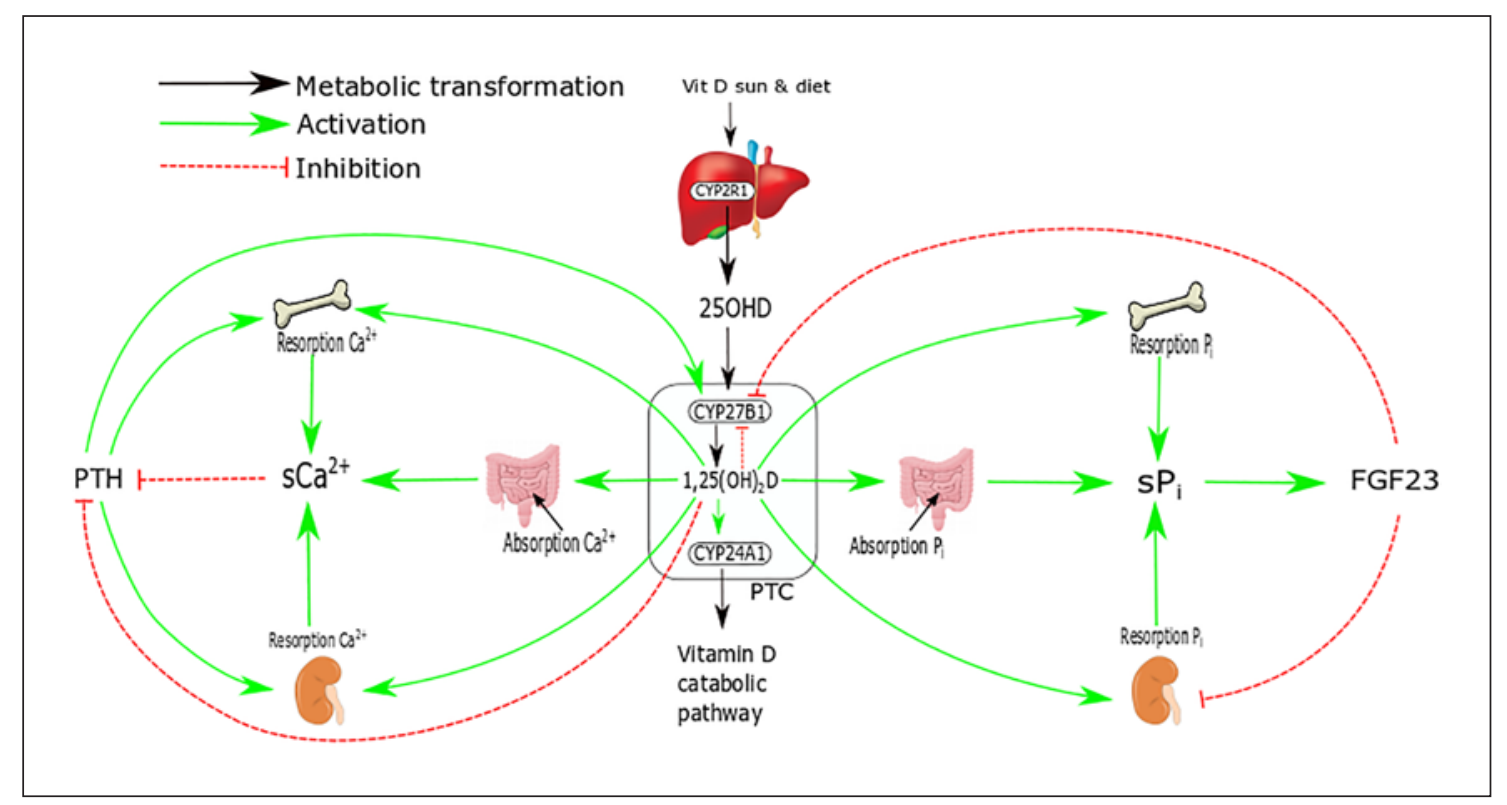

Fig. 2. Physiological regulation of calcium and phosphate metabolism. $1,25(\mathrm{OH})_{2} \mathrm{D}$ activated by CYP27B1 increases resorption of bones, therefore increasing $\mathrm{sCa}^{2+}$ and $\mathrm{sP}_{\mathrm{i}}$ concentration. It also increases calcium and phosphate reabsorption in the kidneys and absorption from the gut. PTH can increase bone and kidney mineral resorption as well as CYP27B1 levels and activity, establishing a feedback loop. All these mechanisms increase $\mathrm{sCa}^{2+}$ and $\mathrm{sP}_{\mathrm{i}}$. Excess of $\mathrm{sCa}^{2+}$ and $1,25(\mathrm{OH})_{2} \mathrm{D}$ inhibits $\mathrm{PTH}$ production. On the

\section{Regulation of CYP27B1 Activity}

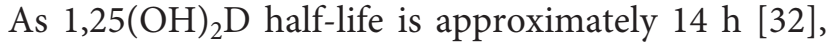
therefore, renal CYP27B1 activity must be tightly regulated. The main regulators include $\mathrm{Ca}^{2+}, \mathrm{PO}_{4}{ }^{3-}$, parathyroid hormone $(\mathrm{PTH})$, and fibroblast growth factor 23 (FGF23). A decrease in $\mathrm{Ca}^{2+}$ stimulates secretion of $\mathrm{PTH}$, stimulating production and activity of CYP27B1 [33]. During normocalcaemia, circulating levels of PTH are insufficient to induce CYP27B1 expression. Hence, calcitonin regulation takes place [34]. Hyperphosphataemia stimulates FGF23 production in the bone. FGF23 inhibits CYP27B1 activity and indirectly decreases serum $\mathrm{PO}_{4}{ }^{3-}$ by downregulation of transcription, translation, and translocation of sodium-phosphate co-transporters in the proximal tubule $[35,36] .1,25(\mathrm{OH})_{2} \mathrm{D}$ itself inhibits CYP27B1 transcription, since CYP27B1, same as the CYP24A1 gene, contains vitamin $\mathrm{D}$ responsive element (VDRE) in a promoter region, establishing a negative feedback loop [26]. In fact, CYP24A1 regulates $1,25(\mathrm{OH})_{2} \mathrm{D}$ production independently on $\mathrm{Ca}^{2+}$ or $\mathrm{PO}_{4}{ }^{3}$. Excess of $1,25(\mathrm{OH})_{2} \mathrm{D}$ downregulates CYP27B1 and upregulates CYP24A1 leading to its degradation. Depend- contrary, increased serum phosphate increases the production of FGF23, which inhibits resorption of phosphate from the kidneys and CYP27B1 activity. The excess of $1,25(\mathrm{OH})_{2} \mathrm{D}$ activates CYP24A1 and inhibits CYP27B1, establishing a negative feedback loop. $\mathrm{sCa}^{2+}$, serum calcium; $\mathrm{sP}_{\mathrm{i}}$, serum phosphate; $\mathrm{PTH}$, parathyroid hormone; FGF23, fibroblast growth factor 23; PTC, proximal tubule cell.

ing on increased FGF23 level, PTH stimulates degradation of its mRNA. Vitamin D metabolism is strictly controlled to avoid an excessive amount of calcitriol [26,37] which could lead to hypercalcaemia and hyperphosphataemia which in turn can be responsible for soft-tissue calcification and formation of kidney stones in the long term [1]. Renal regulation of CYP27B1 is shown in Figure 2. Extrarenal CYP27B1 are regulated by different mechanisms, including tissue-specific factors like cytokines [26].

\section{Transport of Vitamin D}

VDBP and albumin are the primary transporters of vitamin $\mathrm{D}$ metabolites in plasma. VDBP plasma concentrations are 2 orders of magnitude higher $\left(5 \times 10^{-6} \mathrm{M}\right)$ compared to its major circulating ligand $25(\mathrm{OH}) \mathrm{D}(5 \times$ $10^{-8} \mathrm{M}$ ), suggesting that only about $2 \%$ of VDBP is saturated. Under normal condition, $<0.1 \%$ of $25(\mathrm{OH}) \mathrm{D}$ and $<1 \% 1,25(\mathrm{OH})_{2} \mathrm{D}$ are present in free form $[12,29,38]$. Free vitamin D metabolites are crucial for most of the vi- 
Table 2. Recommendations on reference values of vitamin D

\begin{tabular}{llll}
\hline $\begin{array}{l}\text { Deficiency, } \\
\mathrm{ng} / \mathrm{mL}\end{array}$ & $\begin{array}{l}\text { Insufficiency, } \\
\mathrm{ng} / \mathrm{mL}\end{array}$ & $\begin{array}{l}\text { Sufficiency, } \\
\mathrm{ng} / \mathrm{mL}\end{array}$ & Institute \\
\hline$<10$ & & $>10$ & SACN \\
$<20$ & $21-29$ & $>30$ & $\begin{array}{l}\text { NIH, Endocrine } \\
\text { Society, KDOQI }\end{array}$ \\
$<25$ & $<40$ & $>40$ & Vitamin D Society \\
$<12$ & $12-20$ & $>20$ & IoM \\
\hline
\end{tabular}

SACN, Scientific Advisory Committee on Nutrition; NIH, National Institute of Health; KDOQI, Kidney Disease Outcomes Quality Initiative; IoM, Institute of Medicine.

tamin D effects besides metabolites bound to DBP are not available for most of the cells. Later research found that several tissues can transport vitamin D metabolites bound to VDBP into cells due to the megalin/cubilin transporting system. This system is present in kidneys PTC where it reabsorbs VDBP from primary urine, and this mechanism helps to maintain VDBP plasma concentration (Fig. 1) [27]. First finding of the crucial importance of the megalin transporter has been demonstrated by Nykjaer et al. [39] when they knocked out the gene for the megalin transporter in the mouse. Only $2 \%$ of megalin $^{-1-}$ mice survived to adulthood. They were significantly retarded in growth and exhibited a severe reduction in bone density caused by high VDBP and 25(OH)D urine excretion due to the missing megalin transporter compared to control animals. A study published 2 years later demonstrated that cubilin and megalin are physiologically important transporters working together. Cubilin-deficient dogs show 45 and $70 \%$ reduction in plasma $25(\mathrm{OH}) \mathrm{D}$ and $1,25(\mathrm{OH})_{2} \mathrm{D}$, respectively, compared to healthy controls [40].

Megalin/cubilin transporting system also occurs in other tissues like the intestinal cells, placenta, and visceral yolk sac cells. Megalin is widely expressed across the body. It has also been found in the epithelium of the eye, thyroid and parathyroid glands, endometrium and lung alveoli, and many others [41].

\section{Mechanism of Vitamin D Action}

$1,25(\mathrm{OH})_{2} \mathrm{D}$ as a steroid hormone enters the cells via passive diffusion across the cytoplasmatic membrane and enters the cell core in the same way where it binds to VDR $[9,42]$. VDR is a member of a large protein family that includes steroid hormones, vitamin A family metabolites, isoprenoids, fatty acid, thyroid hormones, and eicosanoids. Many receptors of this protein family have not known ligands and are called orphan receptors [12]. VDR acts in concert with other nuclear hormone receptors, mainly the retinoid $\mathrm{X}$ receptor. The heterodimer vitamin D-VDR binds to the VDRE and acts as a transcription factor. VDREs are commonly distributed across the genome and encode proteins that determine detoxification, bone metabolism (growth and remodelling), cell proliferation and differentiation, apoptosis, mammalian hair cycle, lipid metabolism, mineral homeostasis, immune and central nervous system function, and longevity [43]. Up to $10 \%$ of human genes are directly or indirectly responsive to VDR and $1,25(\mathrm{OH})_{2} \mathrm{D}[1,44]$.

Most of the VDRE ( $>98 \%$ ) are located around 400-500 base pairs upstream or downstream of the transcriptional start site of the vitamin $\mathrm{D}$ responsive gene $[9,43]$. A typical sequence of VDRE is a tandem repeating oligonucleotide of 6 base pairs including a 3-nucleotide spacer. This repetition can slightly differ between genes within the genome or species (for more details, see $[9,43]$ ).

As mentioned above, vitamin D has non-genomic effects as well. They include the activation of signalling molecules (e.g., phospholipase C, phospholipase A, and phosphatidylinositol-3 kinase) as well as quick generation of secondary messengers (e.g., $\mathrm{Ca}^{2+}$ and phosphatidylinositol 3,4,5 trisphosphate). $\mathrm{Ca}^{2+}$ and $\mathrm{Cl}^{-}$channels are vitamin D responsive as well [45].

\section{Vitamin D Deficiency and Insufficiency}

Ross et al. [46] published a recommendation for vitamin D plasma levels in 2011 concluding that vitamin D (measured as total 25(OH)D) at plasma concentration 16 $\mathrm{ng} / \mathrm{mL}$ meets the needs of approximately $50 \%$ of the population, and $20 \mathrm{ng} / \mathrm{mL}$ covers $97.5 \%$ of the population. Moreover, the concentration above $50 \mathrm{ng} / \mathrm{mL}$ can cause adverse effects. Historically, vitamin D deficiency and insufficiency were not clearly defined (Table 2). The authors usually suggest vitamin D deficiency as $25(\mathrm{OH}) \mathrm{D}$ plasma concentration $<20 \mathrm{ng} / \mathrm{mL}$, insufficiency as $21-29$ $\mathrm{ng} / \mathrm{mL}$, and optimal level of $25(\mathrm{OH}) \mathrm{D}$ above $30 \mathrm{ng} / \mathrm{mL}$ [47-49]. Previous research found that the ideal physiological concentration of PTH in plasma is achieved when $25(\mathrm{OH}) \mathrm{D}$ is above $32 \mathrm{ng} / \mathrm{mL}[50]$.

Several factors affect vitamin D status, such as sun exposure, skin pigmentation (less pigment allowing to synthesize more previtamin D), time of day, season, area of 
skin exposed to sunlight, body weight (only $1 \%$ of body fat increase was associated with $0.46 \pm 0.22 \mathrm{ng} / \mathrm{mL}$ reduction in circulating $25(\mathrm{OH}) \mathrm{D}$ [51]), latitude, food-related vitamin $\mathrm{D}$ intake, and age (older people synthesizing less previtamin D) [48, 52]. Recommended daily intake and tolerable upper intake of vitamin D for adults are $600 \mathrm{IU} /$ day and 4,000 IU/day, respectively [53]. Nevertheless, even doses around 10,000 IU/day are usually not associated with any adverse side effects. Overdose with vitamin D can cause hypercalcaemia and acute kidney injury, and it is usually caused by dosage equal or above 50,000 IU/ day for a couple of weeks or months [46]. The recent study documented 19 people overdosed with vitamin D [54] with the average daily intake 100,000 IU/day orally or intramuscularly for 5-14 weeks.

Most popular supplements of vitamin D are cholecalciferol and ergocalciferol. In the 1930s, they were both assumed to be equal for humans, but in the second half of last century, pieces of evidence about cholecalciferol being a better option started to accumulate. Recently, cholecalciferol is preferred as a dietary vitamin D supplement. Trang et al. [55] showed that cholecalciferol could increase plasma $25(\mathrm{OH}) \mathrm{D}$ more effectively than ergocalciferol. Vitamin $\mathrm{D}_{3}$ is also maintaining $25(\mathrm{OH}) \mathrm{D}$ levels higher for a more extended period of time [56]. Recent review summarizing current knowledge about $25(\mathrm{OH}) \mathrm{D}$ supplementation suggests even higher efficiency of cholecalciferol in increasing plasma 25(OH)D levels compared to ergocalciferol with 1.7 to 8 higher potency depending on dosage, different pharmacokinetics, and basal 25(OH)D levels [52].

\section{Vitamin D, T2DM, and DKD}

T2DM is considered to induce and maintain a lowgrade chronic inflammation as a consequence of metabolic derangements related to decreased insulin sensitivity and impaired insulin secretion. Monocyte chemoattractant protein 1 is a chemokine produced by mesangial cells and renal tubular cells that play a crucial role in the recruitment of macrophages into the kidney, causing low-grade inflammation [57]. Together with many other pathways, vitamin D is implicated in the development of tissue and organ diabetic complications. Observational studies and some meta-analysis suggest that vitamin D deficiency increases the risk of T2DM development and the incidence of its complication $[58,59]$. Vitamin D can stimulate transcription of the insulin receptor, insulin itself, and its concomitant secretion but also suppresses transcription of monocyte chemoattractant protein 1, therefore decreases inflammatory load to the kidneys [57]. As described above, low levels of vitamin D can cause hyperparathyroidism leading to dephosphorylation of glucose transporter-4 with subsequent decreased insulin-stimulated glucose transport. Therefore, vitamin D supplementation appears a promising strategy to prevent T2DM development (for more details, see [59]). However, a metaanalysis of published interventional studies with vitamin D supplementation in diabetic patients brings (rather typically) contradictory results. For example, $\mathrm{Wu}$ et al. [60] found that vitamin $\mathrm{D}$ supplementation significantly decreases $\mathrm{HbA}_{1 \mathrm{c}}$ and fasting blood glucose levels in non-obese patients with T2DM and overt vitamin D deficiency, but not in those without insufficiency. On the contrary, a more recent meta-analysis did not find any statistically significant changes in $\mathrm{HbA}_{1 \mathrm{c}}$ and fasting blood glucose levels [61]. A recent doubleblind randomized clinical trial showed decreased insulin sensitivity after 6 months of cholecalciferol supplementation measured as HOMA-IR and also lower insulin levels [62]. These different results are probably due to different meta-analysis approach, leaving space for further research.

$\mathrm{DKD}$ is a common microvascular complication of diabetes mellitus with an incidence of approximately 30 $40 \%$. DKD is a major cause of the ESRD, renal transplantation, and mortality among patients with diabetes mellitus [63]. DKD is morphologically characterized by both glomerular (thickening of the glomerular basement membrane, expansion of the mesangium, glomerulosclerosis, and podocyte injury) and tubular changes, but the exact pathogenic mechanism - likely multiple and slightly different in T1DM versus T2DM - is still poorly understood [64]. Furthermore, significant inter-individual variability in the extent and type of glomerular/tubular involvement has been documented with genetic factors suspected to play a role [65].

Haemodynamic alterations, glucose and lipid metabolism disorders, non-enzymatic glycation, polyol pathway, proinflammatory cytokines, and oxidative stress were reported to be responsible for DKD onset and progression. However, present research suggests that abnormal inflammatory response is a crucial contributor to this disease [64]. Vila Cuenca et al. [66] recently showed that paricalcitol (a synthetic vitamin D analogue) modulates the endothelial barrier by enforcement of junctional VEcadherin and the cortical F-actin cytoskeleton thus stabilizing the endothelial barrier in vitro. Vitamin $\mathrm{D}$ also acts 
as a renin-angiotensin-aldosterone system (RAAS) inhibitor, and its insufficiency can lead to increase of RAAS activity and eventually harm the renal tissues [67]. RAAS system is involved in the pathogenesis of DKD, and its inhibition is commonly used in patients with T2DM. A recent meta-analysis found that active vitamin $\mathrm{D}$ analogues in combination with RAAS inhibitors reduced proteinuria by $16 \%$ compared to standard RAAS-blocking therapy [68].

Several studies reported significantly decreased $25(\mathrm{OH}) \mathrm{D}$ plasma levels in a patient with DKD [69], leading to vitamin $\mathrm{D}$ insufficiency or deficiency overtime via several mechanisms: (i) the reduction in the number of functional nephrons. Second, (ii) CYP24A1 is overexpressed in diabetic patients, leading to elevated degradation of the principal vitamin D metabolite. Furthermore, (iii) CYP27B1 activity is decreased probably due to increased FGF23 levels - simultaneously increasing CYP24A1 transcription. Finally, (iv) proteins lost in urine including VDBP, megalin, and cubilin are all essential for vitamin D homeostasis [67]. All these factors result in impaired vitamin $\mathrm{D}$ homeostasis and decrease the level of both $25(\mathrm{OH}) \mathrm{D}$ and $1,25(\mathrm{OH})_{2} \mathrm{D}$ and cause secondary hyperparathyroidism.

A recent meta-analysis did not find any significant protecting effect of cholecalciferol or calcitriol supplementation in patients with DKD [3]. In contrast, another meta-analysis found a significant decrease in albuminuria after 24 weeks of paricalcitol supplementation $(2 \mu \mathrm{g} /$ day) [70]. Based on the current knowledge, despite the widespread belief that maintaining an optimal level of vitamin $\mathrm{D}$ might help to prevent diabetes mellitus and its complications, current evidence-based knowledge does not support a widespread vitamin $\mathrm{D}$ supplementation in diabetic patients $[3,59]$. A recent long-term observational study found that T2DM patients with $25(\mathrm{OH}) \mathrm{D}<12$ $\mathrm{ng} / \mathrm{L}$ are at higher risk of cardiovascular mortality than those with higher 25(OH)D levels [71]. Further research is definitely required to clarify vitamin $\mathrm{D}$ effects on T2DM subtypes and various phenotypes of its complications.

\section{Inhibition of Glucose Reabsorption in the Kidney and Vitamin D}

Sodium-glucose linked co-transporter 2 (SGLT2) inhibitors (SGLT2i), also called gliflozins, are a relatively new class of drugs used as anti-diabetic treatment (with a realistic potential for repurposing to a non-diabetic pop- ulation in the future). It acts via the inhibition of SGLT2 expressed in the proximal tubule. SGLT2 is responsible for reabsorption of up to $97 \%$ of glucose from primary urine (approximately $180 \mathrm{~g} /$ day under healthy condition). SGLT2i decrease glucose reabsorption approximately by $40-60 \%$, thus producing glucosuria and subsequent decrease of glycaemia $[72,73]$. Besides, as shown with many recent studies, SGLT2i are also able to decrease the following parameters: $\mathrm{HbA}_{1 \mathrm{c}}(-0.79 \%$ [95\% CI: $-0.96 \%$ to $-0.62 \%]$ ), weight $(-1.74 \mathrm{~kg}$ [95\% CI: -2.03 to $-1.45 \mathrm{~kg}$ ]) [74], albuminuria $(-43 \%$ [95\% CI: $-54 \%$ to $-31 \%]$ ] [75], systolic blood pressure $(-3.77 \mathrm{~mm} \mathrm{Hg}$ [95\% CI: -4.65 to $-2.90 \mathrm{~mm} \mathrm{Hg}$ ]) [74], and plasma uric acid levels (by $10-15 \%$ depending on dosage) [76]. By contrast, some adverse effects have been reported, for example, increased LDL cholesterol, increased risk of urinary infections with a hazard ratio (HR) (1.43 [95\% CI: 1.051.94]) compared to placebo, and genital tract infection with HR (3.48 [95\% CI: 2.33-5.20]) compared to placebo [74]. Gliflozins only rarely cause diabetic ketoacidosis (HR 10.80 [95\% CI: 1.39-83.65]) [77]. Interestingly, two meta-analyses reported an increased risk of breast cancer in patients using gliflozins $[74,77]$.

Some authors also suggest the possibility of disrupted bone metabolism; inhibiting co-transport of $\mathrm{Na}^{+}$and glucose might increase the electrochemical gradient for sodium in the proximal tubule. Excess of sodium boosts phosphate reabsorption via SLC34A1 $\left(\mathrm{NaP}_{\mathrm{i}}\right.$-IIa) and SLC34A3 ( $\mathrm{NaP}_{\mathrm{i}}$-IIc) co-transporters, and increased phosphate levels induce FGF23 expression. As mentioned above, FGF23 suppresses CYP27B1 expression and induces CYP24A1 expression. Therefore, circulating levels of $1,25(\mathrm{OH})_{2} \mathrm{D}$ might decrease. Lower $1,25(\mathrm{OH})_{2} \mathrm{D}$ levels reduce calcium absorption from the gastrointestinal tract, thereby promote secretion of PTH $[35,78]$. Disruption of the PTH-vitamin D-FGF23 axis may lead to bone demineralization. Recent studies showed decreased levels of calcitriol and increased PTH and FGF23 in both diabetic patients and healthy controls $[75,78]$. On the other hand, a recent meta-analysis did not find an increased risk for bone fracture $[77,79]$.

A recent study observed the effect of canagliflozin on bone mineral density (BMD) and bone biomarkers in a patient with type 2 diabetes [80]. A total of 716 patients followed for up to 104 weeks were divided into three groups receiving placebo and 100 and $300 \mathrm{mg}$ of canagliflozin administered once daily. The authors found statistically significant differences in total hip BMD between placebo and both experimental groups with hip BMD decrease by 0.9 and $1.2 \%$ in the $100-$ and $300-\mathrm{mg}$ 
canagliflozin group, respectively. No other statistical significances were found in measured parameters related to bone metabolism. The study also measured oestradiol, a hormone causing bone demineralization when its plasma levels are decreased. Compared to the placebo group, oestradiol decreased by 14.2 and $21.0 \%$ in 100- and 300-mg canagliflozin groups, respectively, at week 52. Canagliflozin use was also associated with increased $\beta$-CTX, a serum bone resorption marker. Interestingly, osteocalcin, a serum bone formation marker, was also increased significantly in both 100 - and 300 -mg canagliflozin groups compared to placebo at week 52. These results suggest augmented bone turnover in patients treated with canagliflozin, and further research is needed to elucidate the clinical significance of these findings.

\section{Conclusions}

Vitamin D and its metabolites play a crucial role in human health. Vitamin D is involved in calcium and phosphate homeostasis, and up to $10 \%$ of our genome is responsive to $1,25(\mathrm{OH})_{2} \mathrm{D}$. Given the vitamin $\mathrm{D}$ deficiency/ insufficiency and T2DM prevalence growing worldwide in the last decades, health burden for health care systems might be aggravated by their mutual pathophysiological interconnections. It is well documented that patients with DKD are excreting vitamin D and VDBP via urine, suggesting impairment of reuptake in PTC. Despite the broad range of established beneficial vitamin $\mathrm{D}$ effects in diabetes and CKD/DKD settings and thus importance to maintain physiological concentration in plasma, no definite conclusions can be drawn from the current literature on benefits of vitamin D supplementation in these individuals. Despite widespread recognized safety of SGLT2i, recent evidence suggests disruption of the PTH-vitamin D-FGF23 axis, resulting in impaired bone metabolism. Further research is needed to provide evidence about seriousness of metabolic disruption and its consequences.

\section{Conflict of Interest Statement}

The authors declare no conflicts of interest.

\section{Funding Sources}

The study was supported by the NV18-01-00046 from the Ministry of Health of the Czech Republic.

\section{Author Contributions}

The authors have contributed to the writing of this manuscript in the following way: conceptualization: David Galuška. Writing the original draft: David Galuška and Lukáš Pácal. Reviewing and editing final manuscript: David Galuška, Lukáš Pácal, and Kateřina Kaňková. All the authors contributed equally to the writing of the manuscript.

\section{References}

1 Hossein-Nezhad A, Holick MF. Vitamin D for health: a global perspective. Mayo Clin Proc. 2013 Jul;88(7):720-55.

2 Prentice A. Vitamin D deficiency: a global perspective. Nutr Rev. 2008 Oct;66(10 Suppl 2):S153-64.

3 Derakhshanian H, Shab-Bidar S, Speakman JR, Nadimi H, Djafarian K. Vitamin D and diabetic nephropathy: a systematic review and meta-analysis. Nutrition. 2015 Oct; 31(10):1189-94.

4 Senyigit A. The association between 25-hydroxy vitamin $\mathrm{D}$ deficiency and diabetic complications in patients with type 2 diabetes mellitus. Diabetes Metab Syndr. 2019 Mar 1; 13(2):1381-6.

5 Ali MI, Fawaz LA, Sedik EE, Nour ZA, Elsayed RM. Vitamin D status in diabetic patients (type 2) and its relation to glycemic control \& diabetic nephropathy. Diabetes Metab Syndr. 2019 May - Jun;13(3):1971-3.
6 Lytvyn Y, Bjornstad P, van Raalte DH, Heerspink HL, Cherney DZI. The new biology of diabetic kidney disease: mechanisms and therapeutic implications. Endocr Rev. 2019 Oct 21;41:202-31.

7 Martineau AR, Jolliffe DA, Hooper RL, Greenberg L, Aloia JF, Bergman P, et al. Vitamin D supplementation to prevent acute respiratory tract infections: systematic review and meta-analysis of individual participant data. BMJ. 2017 Feb 15;356:i6583 [cited 2020 May 21].

8 Alipio M. Vitamin D supplementation could possibly improve clinical outcomes of patients infected with coronavirus-2019 (COVID-19) [Internet]. Rochester, NY: Social Science Research Network; 2020 Apr [cited 2020 May 15]. Report No.: ID 3571484. Available from: https://papers.ssrn.com/abstract=3571484.
9 Makin HLJ, Jones G, Kaufmann M, Calverley MJ. Analysis of vitamins D, their metabolites and analogues. In: Makin HLJ, Gower DB, editors. Steroid analysis [Internet]. Dordrecht, Netherlands: Springer; 2010. p. 9671096 [cited 2019 Jun 19]

10 Smith JE, Goodman DS. The turnover and transport of vitamin D and of a polar metabolite with the properties of 25-hydroxycholecalciferol in human plasma. J Clin Invest. 1971 Oct;50(10):2159-67.

11 Kotsa K, Grammatiki M. Chapter 10: the role of vitamin $\mathrm{D}$ in the prevention and treatment of diabetes mellitus. In: Watson RR, Preedy VR, editors. Bioactive food as dietary interventions for diabetes (second edition) [Internet]. Cambridge: Academic Press; 2019. p. 157-74 [cited 2019 May 21]. Available from: http://www.sciencedirect. c o m/ s cie nce/a r ticle/pii/ B9780128138229000102. 
12 Bikle D. Vitamin D: production, metabolism, and mechanisms of action. In: Feingold KR, Anawalt B, Boyce A, Chrousos G, Dungan K, Grossman A, et al. editors. Endotext [Internet]. South Dartmouth, MA: MDText.com; 2017 [cited 2019 May 21]. Available from: http://www.ncbi.nlm.nih.gov/books/ NBK278935/.

13 Cheng JB, Motola DL, Mangelsdorf DJ, Russell DW. De-orphanization of cytochrome P450 2R1: a microsomal vitamin D 25-hydroxilase. J Biol Chem. 2003 Sep 26;278(39): 38084-93.

14 Miller WL, Portale AA. Vitamin D 1 alphahydroxylase. Trends Endocrinol Metab. 2000 Oct 1;11(8):315-9.

15 Boron W, Boulpaep E Medical physiology. 3rd ed. Philadeplhia: Elsevier; 2017. p. 1297.

16 Cheng JB, Levine MA, Bell NH, Mangelsdorf DJ, Russell DW. Genetic evidence that the human CYP2R1 enzyme is a key vitamin D 25-hydroxylase. Proc Natl Acad Sci U S A. 2004 May 18;101(20):7711-5.

17 Takeyama K, Kitanaka S, Sato T, Kobori M, Yanagisawa J, Kato S. 25-Hydroxyvitamin D3 1alpha-hydroxylase and vitamin D synthesis. Science. 1997 Sep 19;277(5333):1827-30.

18 Jones G, Prosser DE, Kaufmann M. 25-Hydroxyvitamin D-24-hydroxylase (CYP24A1): its important role in the degradation of vitamin D. Arch Biochem Biophys. 2012 Jul 1; 523(1):9-18.

19 Horst RL. 25-OHD3-26,23-lactone: a metabolite of vitamin D3 that is 5 times more potent than 25-OHD3 in the rat plasma competitive protein binding radioassay. Biochem Biophys Res Commun. 1979 Jul 12;89(1):286-93.

20 Ross AC, Yaktine AL, Valle HBD. Overview of vitamin D [Internet]. Washington, DC: National Academies Press; 2011 [cited 2019 Jun 3]. Available from: https://www.ncbi. nlm.nih.gov/books/NBK56061/.

21 Prosser DE, Kaufmann M, O'Leary B, Byford V, Jones G. Single A326G mutation converts human CYP24A1 from 25-OH-D3-24-hydroxylase into -23-hydroxylase, generating 1alpha,25-(OH)2D3-26,23-lactone. Proc Natl Acad Sci U S A. 2007 Jul 31;104(31):12673-8.

22 Ishizuka S, Kurihara N, Hiruma Y, Miura D, Namekawa J, Tamura A, et al. 1alpha,25-Dihydroxyvitamin $\mathrm{D}(3)$-26,23-lactam analogues function as vitamin $D$ receptor antagonists in human and rodent cells. J Steroid Biochem Mol Biol. 2008 Jun;110(3-5):269-77.

23 Masuda S, Byford V, Arabian A, Sakai Y, Demay MB, St-Arnaud R, et al. Altered pharmacokinetics of 1alpha,25-dihydroxyvitamin D3 and 25-hydroxyvitamin D3 in the blood and tissues of the 25-hydroxyvitamin D-24-hydroxylase (Cyp24a1) null mouse. Endocrinology. 2005 Feb;146(2):825-34.
24 St-Arnaud R, Arabian A, Travers R, Barletta F, Raval-Pandya M, Chapin K, et al. Deficient mineralization of intramembranous bone in vitamin D-24-hydroxylase-ablated mice is due to elevated 1,25-dihydroxyvitamin $\mathrm{D}$ and not to the absence of 24,25-dihydroxyvitamin D. Endocrinology. 2000 Jul;141(7):2658-66.

25 Prosser DE, Jones G. Enzymes involved in the activation and inactivation of vitamin $\mathrm{D}$. Trends Biochem Sci. 2004 Dec 1;29(12):66473.

26 Jones G, Prosser DE, Kaufmann M. Cytochrome P450-mediated metabolism of vitamin D. J Lipid Res. 2014 Jan;55(1):13-31.

27 Nielsen R, Christensen EI, Birn H. Megalin and cubilin in proximal tubule protein reabsorption: from experimental models to human disease. Kidney Int. 2016 Jan;89(1):5867.

28 Chesney RW. Interactions of vitamin D and the proximal tubule. Pediatr Nephrol. 2016 Jan;31(1):7-14.

29 Cooke NE, Haddad JG. Vitamin D binding protein (Gc-globulin). Endocr Rev. 1989 Aug 1;10(3):294-307.

30 Bikle DD. Extra renal Ssnthesis of 1,25-dihydroxyvitamin D and its health implications. Clinic Rev Bone Miner Metab. 2009 Jun 1; 7(2):114-25.

31 Zehnder D, Bland R, Williams MC, McNinch RW, Howie AJ, Stewart PM, et al. Extrarenal expression of 25-hydroxyvitamin d(3)-1 alpha-hydroxylase. J Clin Endocrinol Metab. 2001 Feb;86(2):888-94.

32 Barbara Mawer E, Davies M, Backhouse J, Hill LF, Taylor CM. Metabolic fate of administered 1,25-dihydroxycholecalciferol in controls and in patients with hypoparathyroidism. Lancet. 1976 Jun 5;307(7971):1203-6.

33 Brenza HL, Kimmel-Jehan C, Jehan F, Shinki T, Wakino S, Anazawa H, et al. Parathyroid hormone activation of the 25-hydroxyvitamin D3-1alpha-hydroxylase gene promoter. Proc Natl Acad Sci U S A. 1998 Feb 17;95(4): 1387-91.

34 Shinki T, Ueno Y, DeLuca HF, Suda T. Calcitonin is a major regulator for the expression of renal 25-hydroxyvitamin D3-1alpha-hydroxylase gene in normocalcemic rats. Proc Natl Acad Sci U S A. 1999 Jul 6;96(14):82538.

35 Blau JE, Collins MT. The PTH-vitamin DFGF23 axis. Rev Endocr Metab Disord. 2015 Jun 1;16(2):165-74.

36 Liu S, Quarles LD. How fibroblast growth factor 23 works. J Am Soc Nephrol. 2007 Jun 1; 18(6):1637-47.

37 Kägi L, Bettoni C, Pastor-Arroyo EM, Schnitzbauer U, Hernando N, Wagner CA. Regulation of vitamin $\mathrm{D}$ metabolizing enzymes in murine renal and extrarenal tissues by dietary phosphate, FGF23, and 1,25(OH)2D3. PLoS One. 2018;13(5):e0195427.
38 Dastani Z, Berger C, Langsetmo L, Fu L, Wong BY, Malik S, et al. In healthy adults, biological activity of vitamin $\mathrm{D}$, as assessed by serum PTH, is largely independent of DBP concentrations. J Bone Miner Res. 2014;29(2): 494-9.

39 Nykjaer A, Dragun D, Walther D, Vorum H, Jacobsen C, Herz J, et al. An endocytic pathway essential for renal uptake and activation of the steroid 25- $(\mathrm{OH})$ vitamin D3. Cell. 1999 Feb 19;96(4):507-15.

40 Nykjaer A, Fyfe JC, Kozyraki R, Leheste JR, Jacobsen C, Nielsen MS, et al. Cubilin dysfunction causes abnormal metabolism of the steroid hormone $25(\mathrm{OH})$ vitamin $\mathrm{D}(3)$. Proc Natl Acad Sci U S A. 2001 Nov 20;98(24): 13895-900.

41 Christensen EI, Birn H. Megalin and cubilin: multifunctional endocytic receptors. Nat Rev Mol Cell Biol. 2002 Apr;3(4):256.

42 Mendel CM. The free hormone hypothesis: a physiologically based mathematical model. Endocr Rev. 1989 Aug 1;10(3):232-74.

43 Haussler MR, Whitfield GK, Haussler CA, Sabir MS, Khan Z, Sandoval R, et al. Chapter eight: 1,25-dihydroxyvitamin $D$ and klotho: a tale of two renal hormones coming of age. In: Litwack G, editor. Vitamins \& hormones [Internet]. Cambridge: Academic Press; 2016. p. 165-230 [cited 2019 Jun 11] (Vitamin D Hormone; vol. 100). Available from: http://www. sciencedirect.com/science/article/pii/ S0083672915000692.

44 Bouillon R, Carmeliet G, Verlinden L, van Etten E, Verstuyf A, Luderer HF, et al. Vitamin $\mathrm{D}$ and human health: lessons from vitamin D receptor null mice. Endocr Rev. 2008 Oct;29(6):726-76.

45 Hii CS, Ferrante A. The non-genomic actions of vitamin D. Nutrients. 2016 Mar 2;8(3):135.

46 Ross AC, Yaktine AL, Del Valle HB, editors. Dietary reference intakes for calcium and vitamin D [Internet]. Washington, DC: National Academies Press; 2011 [cited 2020 May 21]. The National Academies Collection: Reports funded by National Institutes of Health. Available from: http://www.ncbi.nlm.nih. gov/books/NBK56070/.

47 Holick MF. Vitamin D deficiency. N Engl J Med. 2007 Jul 19;357(3):266-81.

48 Rovner AJ, O'Brien KO. Hypovitaminosis D among healthy children in the United States: a review of the current evidence. Arch Pediatr Adolesc Med. 2008 Jun;162(6):513-9.

49 Sahota O. Understanding vitamin D deficiency. Age Ageing. 2014 Sep;43(5):589-91.

50 Holick MF. The vitamin D epidemic and its health consequences. J Nutr. 2005 Nov; 135(11):2739S-48S. 
51 Lenders CM, Feldman HA, Von Scheven E, Merewood A, Sweeney C, Wilson DM, et al. Relation of body fat indexes to vitamin D status and deficiency among obese adolescents. Am J Clin Nutr. 2009 Sep;90(3):459-67.

52 Cesareo R, Falchetti A, Attanasio R, Tabacco G, Naciu AM, Palermo A. Hypovitaminosis $\mathrm{D}$ : is it time to consider the use of calcifediol? Nutrients. 2019 May 6;11(5).

53 Ross AC, Manson JE, Abrams SA, Aloia JF, Brannon PM, Clinton SK, et al. The 2011 report on dietary reference intakes for calcium and vitamin $D$ from the Institute of Medicine: what clinicians need to know. J Clin Endocrinol Metab. 2011 Jan;96(1):53-8.

54 Chowdry AM, Azad H, Najar MS, Mir I. Acute kidney injury due to overcorrection of hypovitaminosis D: a tertiary center experience in the Kashmir Valley of India. Saudi J Kidney Dis Transpl. 2017 Nov-Dec;28(6): 1321-9.

55 Trang HM, Cole DE, Rubin LA, Pierratos A, Siu S, Vieth R. Evidence that vitamin D3 increases serum 25-hydroxyvitamin D more efficiently than does vitamin D2. Am J Clin Nutr. 1998 Oct;68(4):854-8.

56 Armas LA, Hollis BW, Heaney RP. Vitamin $\mathrm{D} 2$ is much less effective than vitamin D3 in humans. J Clin Endocrinol Metab. 2004 Nov; 89(11):5387-91.

57 Zhang Z, Yuan W, Sun L, Szeto FL, Wong KE, Li X, et al. 1,25-Dihydroxyvitamin D3 targeting of NF-kappaB suppresses high glucoseinduced MCP-1 expression in mesangial cells. Kidney Int. 2007 Jul 2;72(2):193-201.

58 Chiu KC, Chu A, Go VL, Saad MF. Hypovitaminosis $\mathrm{D}$ is associated with insulin resistance and beta cell dysfunction. Am J Clin Nutr. 2004 May;79(5):820-5.

59 Grammatiki M, Karras S, Kotsa K. The role of vitamin $\mathrm{D}$ in the pathogenesis and treatment of diabetes mellitus: a narrative review. Hormones. 2018 Sep 25;18:37-48.

60 Wu C, Qiu S, Zhu X, Li L. Vitamin D supplementation and glycemic control in type 2 diabetes patients: a systematic review and metaanalysis. Metab Clin Exp. 2017 Aug 1;73:6776.

61 Li X, Liu Y, Zheng Y, Wang P, Zhang Y. The effect of vitamin D supplementation on glycemic control in type 2 diabetes patients: a systematic review and meta-analysis. Nutrients. 2018 Mar 19;10(3):375 [cited 2019 Jul 29]. Available from: https://www.ncbi.nlm.nih. gov/pmc/articles/PMC5872793/.
62 Niroomand M, Fotouhi A, Irannejad N, Hosseinpanah F. Does high-dose vitamin D supplementation impact insulin resistance and risk of development of diabetes in patients with pre-diabetes? A double-blind randomized clinical trial. Diabetes Res Clin Pract. 2019 Feb 1;148:1-9.

63 Anders HJ, Huber TB, Isermann B, Schiffer M. CKD in diabetes: diabetic kidney disease versus nondiabetic kidney disease. Nat Rev Nephrol. 2018 Jun;14(6):361-77.

64 Hu X, Liu W, Yan Y, Liu H, Huang Q, Xiao Y, et al. Vitamin $\mathrm{D}$ protects against diabetic nephropathy: evidence-based effectiveness and mechanism. Eur J Pharmacol. 2019 Feb 15; 845:91-8

65 Li M, Pezzolesi MG. Advances in understanding the genetic basis of diabetic kidney disease. Acta Diabetol. 2018 Nov 1;55(11):1093104.

66 Vila Cuenca M, Ferrantelli E, Meinster E, Pouw SM, Kovačević I, de Menezes RX, et al. Vitamin D attenuates endothelial dysfunction in uremic rats and maintains human endothelial stability. J Am Heart Assoc. 2018 Sep 4; 7(17):e008776.

67 Plum LA, Zella JB. Vitamin D compounds and diabetic nephropathy. Arch Biochem Biophys. 2012 Jul 1;523(1):87-94.

68 de Borst MH, Hajhosseiny R, Tamez $H$, Wenger J, Thadhani R, Goldsmith DJA. Active vitamin $\mathrm{D}$ treatment for reduction of residual proteinuria: a systematic review. J Am Soc Nephrol. 2013 Nov 1;24(11):1863-71.

69 Xiao X, Wang Y, Hou Y, Han F, Ren J, Hu Z. Vitamin D deficiency and related risk factors in patients with diabetic nephropathy. J Int Med Res. 2016 Jun;44(3):673-84.

70 de Zeeuw D, Agarwal R, Amdahl M, Audhya P, Coyne D, Garimella T, et al. Selective vitamin D receptor activation with paricalcitol for reduction of albuminuria in patients with type 2 diabetes (VITAL study): a randomised controlled trial. Lancet. 2010 Nov 6;376(9752): 1543-51.

71 Al-khalidi B, Kuk JL, Ardern CI. Lifetime risk of cardiometabolic mortality according to vitamin D status of middle and older-aged adults: NHANES III mortality follow-up. J Steroid Biochem Mol Biol. 2019 Feb 1;186: $34-41$.
72 Satirapoj B. Sodium-glucose cotransporter 2 inhibitors with renoprotective effects. Kidney Dis. 2017 Jul;3(1):24-32.

73 Milder TY, Stocker SL, Samocha-Bonet D, Day RO, Greenfield JR. Sodium-glucose cotransporter 2 inhibitors for type 2 diabetes: cardiovascular and renal benefits in patients with chronic kidney disease. Eur J Clin Pharmacol. 2019 Aug 3;75:1481-90 [cited 2019 Aug 28].

74 Vasilakou D, Karagiannis T, Athanasiadou E, Mainou M, Liakos A, Bekiari E, et al. Sodiumglucose cotransporter 2 inhibitors for type 2 diabetes: a systematic review and meta-analysis. Ann Intern Med. 2013 Aug 20;159(4): 262-74.

75 de Jong MA, Petrykiv SI, Laverman GD, van Herwaarden AE, de Zeeuw D, Bakker SJL, et al. Effects of dapagliflozin on circulating markers of phosphate homeostasis. Clin J Am Soc Nephrol. 2019 Jan 7;14(1):66-73.

76 Bailey CJ, Gross JL, Pieters A, Bastien A, List JF. Effect of dapagliflozin in patients with type 2 diabetes who have inadequate glycaemic control with metformin: a randomised, double-blind, placebo-controlled trial. Lancet. 2010 Jun 26;375(9733):2223-33.

77 Perkovic V, Jardine MJ, Neal B, Bompoint S, Heerspink HJL, Charytan DM, et al. Canagliflozin and renal outcomes in type 2 diabetes and nephropathy. N Engl J Med. 2019 Jun 13; 380(24):2295-306.

78 Blau JE, Bauman V, Conway EM, Piaggi P, Walter MF, Wright EC, et al. Canagliflozin triggers the FGF23/1,25-dihydroxyvitamin $\mathrm{D} / \mathrm{PTH}$ axis in healthy volunteers in a randomized crossover study. JCI Insight. 2018 Apr 19;3(8):e99123.

$79 \mathrm{Wu} \mathrm{JH}$, Foote C, Blomster J, Toyama T, Perkovic V, Sundström J, et al. Effects of sodium-glucose cotransporter-2 inhibitors on cardiovascular events, death, and major safety outcomes in adults with type 2 diabetes: a systematic review and meta-analysis. Lancet $\mathrm{Di}$ abetes Endocrinol. 2016;4(5):411-9.

80 Bilezikian JP, Watts NB, Usiskin K, Polidori D, Fung A, Sullivan D, et al. Evaluation of bone mineral density and bone biomarkers in patients with type 2 diabetes treated with canagliflozin. J Clin Endocrinol Metab. 2016 Jan;101(1):44-51. 